\title{
A Live-working Robot with a Fast Line up And down Function
}

\author{
N.C. Ou, W. Li \& L.F. Li \\ Hunan Provincial Live Working Center of State Grid, Changsha, China \\ S. Zheng \\ Hunan Electric Power Construction Supervision Consulting Corporation, Changsha, China
}

\begin{abstract}
In this paper, mainly research on a Live-working robot in power transmission line, it composed with Live-working robot unit and operation platform. The operation platform use to support the whole robot line up and down. Under the action of machine, insulation winch and the rope concerted action in order to support the power with the whole robot online and offline. The Live-working robot described in this paper can achieve the line up and down function much more convenient and rapidly.
\end{abstract}

KEYWORD: Crossing barrier; Live-working; Robot; Keep the center of gravity

\section{INTRODUCTION}

After electricity is produced through power stations which need to be transmitted through the highvoltage transmission lines, so the high voltage transmission lines spreads each corner in our country, including cities, rural areas, etc. High voltage transmission line generally refers to the voltage at $220 \mathrm{~V}$ or above the voltage. The maintenance of high voltage transmission lines are limited by various conditions, Firstly, There are security risks in direct manual operation because of the line charged. Secondly, due to the environment or topography, there may be a high voltage transmission line that workers is difficult or impossible to touch or close. Based on the above reasons, there is a need for automatic maintenance of high voltage transmission lines, such as power transmission lines maintenance robotic.

At present, the high voltage power transmission lines maintenance robotic is usually used for the inspection of high voltage transmission line, although it can replace manual inspection, and has the advantages of stable operation, high efficiency and so on. But it can not replace workers to carry out basic maintenance operations, for instance, Replacement of insulator string and tighten the clamp bolt, so on. In order to reduce the risk of workers, it can be conceived that the robot is equipped with a robotic arm, and a variety of mechanical arm end to achieve a variety of electric operation. For example, In the patent (the application number is 201410226160.8), a live working robot for high voltage transmission line is disclosed, in which a variety of live working operation is realized by using different terminal devices on the robot arm, the end includes an upper jaw and a lower jaw, and the operation of the clamping jaw is fixed on the plate and the upper jaw is put out or sent to the $\mathrm{W}$ pin.

In the past practice, this type of robot usually rised to the wire by manual and pull, then, hanging the wire through the robot arm. However, in the process of hanging, we need to rotated robot in the horizontal plane to ensure the robot arm can be Up to the top of the wire and not affected by the obstruction of the wire, so as to facilitate the robot manipulator clamping. In related art, usually, the rotation of the live working robot needs to be realized by 5-7 through the pull rope which Wasted of time and manpower. Therefore, an auxiliary tool is needed to operate the robot on-line and off-line to simplify the on-line and off-line operation and improve the system's automaticity and stability.

\section{THE OVERALL DESIGN OF THE ROBOT}

This research is to study a highly automated robot operation platform and the robot body that can provide support for the robot on line and off line, convenient operation and high working stability. The robot has the advantages of simple structure, convenient operation and high working stability.

In this paper, we designed a robot used for live line work. The robot included live working robot body and operation platform. The shape of the working platform of the live working robot is a cube, and a motor is arranged inside the platform. The platform are supporting role When the robot on-line and 
off-line. The operation platform includes an insulating rope and grinding insulation rope which drived by the motor. Wear rope hanging on the wire and passes through the work platform which is connected with the grinding rope winch. Under the action of the motor, two of them provided the lifting force and the support force of the working platform and the rising time of the live working robot.

\section{DESIGN OF UP AND DOWN LINE MODE}

The on-line function of Live working robot mainly use by the abrasive rope winch connecting the motor driven grinding rope winch rotation, so that the live working robot components rise, the friction between the rope and the rope winch grinding mill is large enough to support the robot. After the robot rises to a certain degree, The robot is rotated by the wind turbine based on the robot body or the working platform .The robot manipulator and wire stagger, to enable the robot to rise and make the rotation mechanical arm and wire collinear once again, The pulley on the end of the robot arm falls on the wire. Finally removed the rope and work platform grinding. The offline step is to execute the on-line step by contrast.

To sum up, the development of live working robot is easy to operate, and it can contribute to the charged robot on-line and offline operation, so as to raise the operation stability, save the manpower cost, improve the degree of automation of the whole system, and improve the operating efficiency.

\section{DESIGN OF ROBOT'S STRUCTURE}

The structure of the live working robot for high voltage transmission line is shown in Figure 1. The described in the range expressions such as "horizontal" and "vertical" and "X", "Y" and "Z" axis direction are Relative opposite, the paper will not repeat later in this article. It can be seen from the figure, The robot body 110 is hung on the high voltage transmission line through the mechanical arm 120 and130.The mechanical arm 120 and 130 are arranged on both sides of the high voltage transmission line. Each of mechanical arm 120 and 130 Equipped with pulley near the end of high voltage transmission lines. The pulley comprises walking wheel 121 and 131 for the robot to walk along the high voltage transmission line as well as the potential wheel 122 and 132 for equal potential connection. Walking wheel 121 and 131 is the driving wheel, which used Independent drive and choose the Maxon company's position and current feedback double closed-loop drive device (motor speed reducer - encoder and double closed loop servo drive). In addition, each pulley system also comprises claw
123 and 133 to protect the robot Will not fall from the high voltage transmission lines.

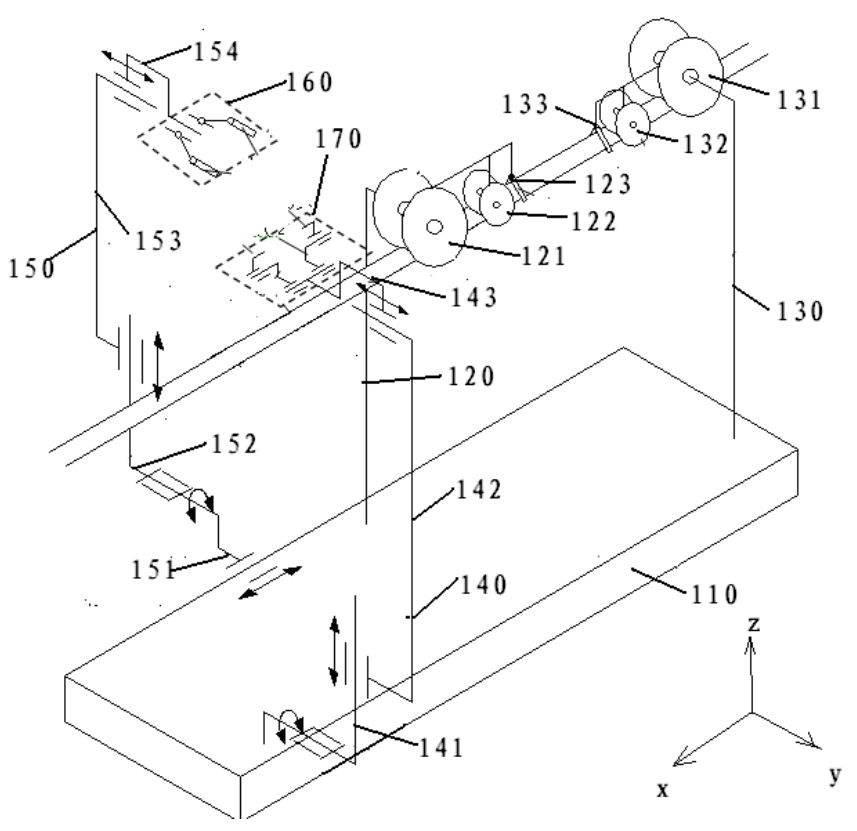

Fig. 1 The overall structure of the live working robot

In the robot's Left front where Equipped with two or more robotic manipulator 140 and 150 , each robot arm 140 and 150 can move along multiple degrees of freedom. Including along the $\mathrm{X}, \mathrm{y}, \mathrm{Z}$ axis translation, around the $\mathrm{X}, \mathrm{y}, \mathrm{Z}$ axis rotation, etc. In brief, each arm is adapted to move the end of the robot arm 160 and 170 to the position to facilitate the execution of the task. The first manipulator 140 is provided with a first mechanical arm rotary joint 141 , a first mechanical arm telescopic joint 142 and a first mechanical arm of the longitudinal movement of the joint 143 . The second mechanical arm 150 is provided with second mechanical arm rotating joint 151 , second mechanical arm rotary joint 152, second mechanical arm telescopic joint 153 and second mechanical hand longitudinal movement joint 154. In addition, the end of the robot arm is used to perform the insulator string replacement task, the first mechanical arm is provided with a W pin 170 which is shown in the patent that mentioned above, and the second mechanical arm is provided with an insulator string push end 160.

In the prior art, we usually use the way of holding make the robot arm 120 and 130 to hang on the wire. Pulling and hanging process requires workers to pull the rope when higher than wire. For example, need 5-7 people to enable the robot to rotate so that robot can rise above the wire. Then, through the human to make the robot rotation so that the pulley of the mechanical arm 120 and 130 at the top of the wire, thereby, the installation of the pulley on the conducting wire is convenient.

In this paper, we study a Live-working Robot with a Fast Line up And Down Function as well as 
the advantages of high automation and saving manpower as shown in Figure 2. The live working robot shown in Figure 1 is marked with number 300 in Figure 2 and the working platform for live working robot shown in Figure 1 is marked with number 300 in Figure 2. The live working robot 300 is supported on the working platform 400, and is supported on the working platform 400 through a free wheel. The upper end of the rope is Insurance lock 308 which can lock to the wire. The insurance 308 can be removed by mechanical arm robot.

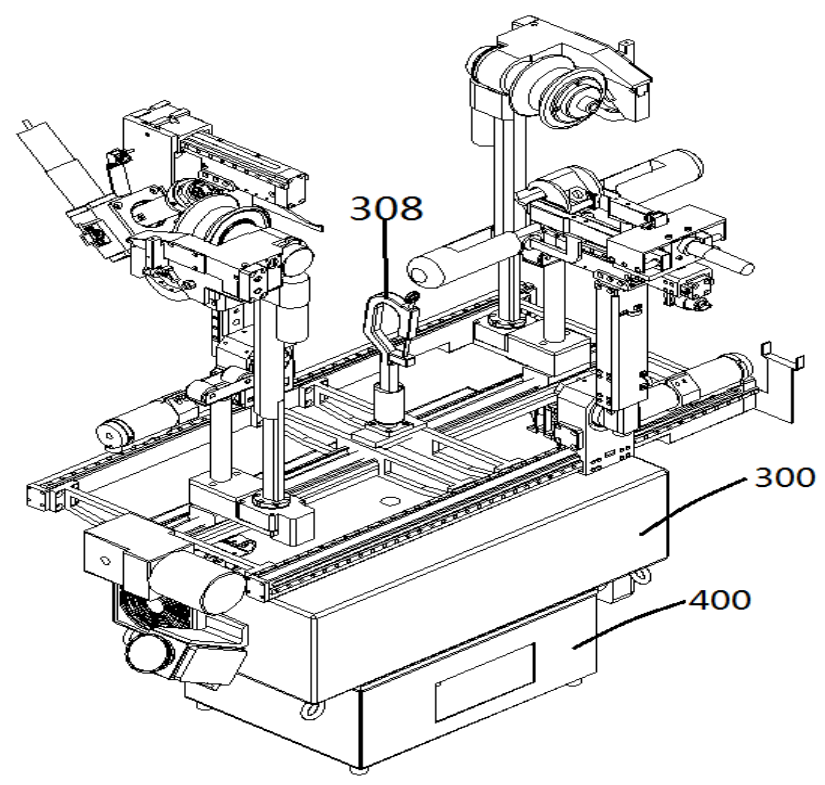

Fig 2 The three-dimensional graph of live working robot

The side view of platform is shown in Figure 3, it includes the grinding rope, the rope and the rope winch grinding 402 are interface, Insulation rope winch mill 402 is driven by a motor drive 401, the end of the wire rope wear and merge from wire suspension. The live working robot 300 together with the operating platform 400 can be along with the rope vertically up to the position which is convenient for hanging on the wire. A free wheel 404 is arranged at the upper part of the working platform 400 to make the charged working robot 300 slide on the working platform 400 . This is very beneficial for the initial positioning of the robot and the center position of the grinding rope.
The side view of the live working robot is shown in Figure 4, On the opposite side of the bottom of the live working robot 300 is provided with a blower 405 to provide the rotation torque to the robot itself in order to achieve the rotation operation in the horizontal plane, the opposite side of the fan 405 can provide two directions of torque, even if the robot 300 can rotate along two directions. Because the operating platform 400 is provided with a free wheel, the rotation of the live working robot 300 does not drive the working platform 400 with larger inertia rotation. But can be freely rotated on the operating platform 400, so the wind turbine can be designed to provide only a smaller torque.

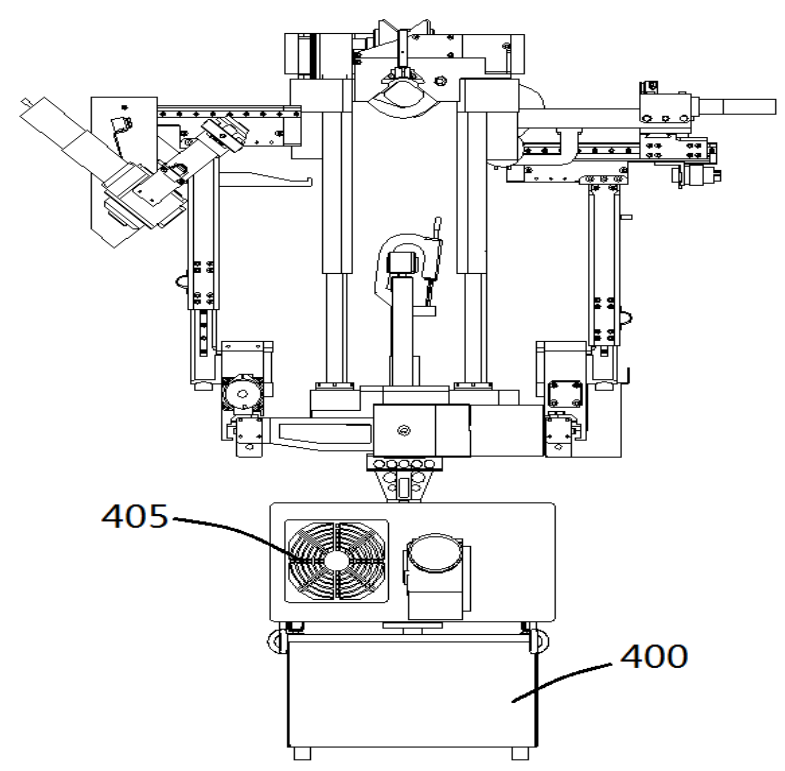

Fig 4 The side view of the live working robot

The side view of the live working robot is shown in Figure 5, the fan 406 can be installed on the opposite side of platform 400, so that the work platform 400 and the robot 300 can rotate together. The operating robot 300 can be fixed to the operating platform 400 so that it can rotate with it. A free wheel and a fixing facility can be arranged on the working platform 400 to fit the two different rotation modes, that is, the blower is installed on the working platform 400 and is installed on the live working robot 300 .

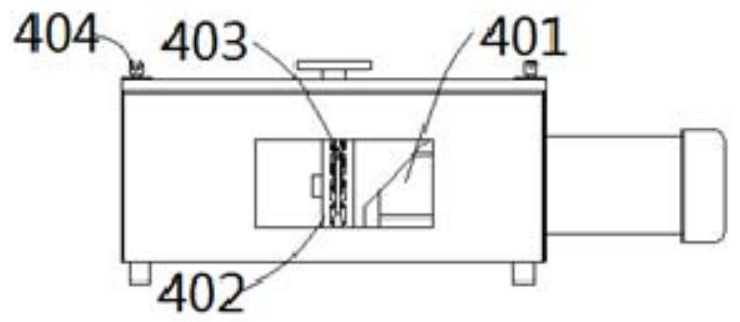

Fig 3 The side view of platform 


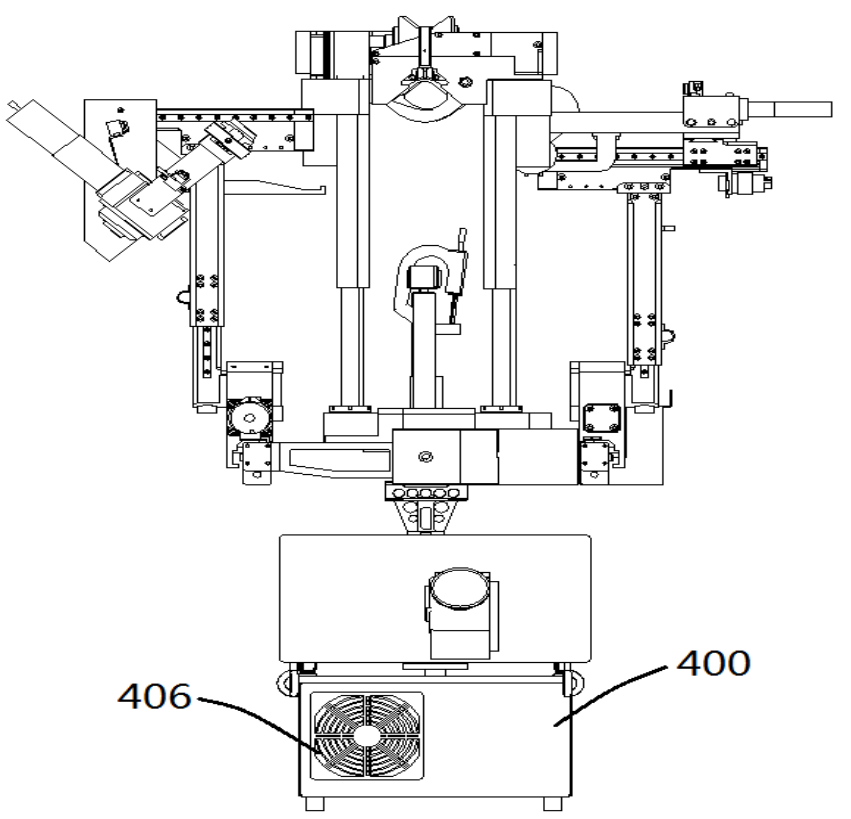

Fig 5 The side view of the live working robot

\section{CONCLUSION}

Through theoretical conception, prototype experiment and on-the-spot investigation, we can find: By using the robot which is discussed in this paper ,live working robot can realize the function of on-line and off-line, improve the operation reliability, and save the labor cost.

\section{REFERENCES}

Aghili F., Parsa K.A reconfigurable robot with lockable cylindrical joints [J]. IEEE Transactions on Robotics, 2009, 25 (4):785-797.

Alutei A., Tatar M. O., CirebeaC. Model and test of a modular inspection robotic system [J]. Mechanika, 2010, 84 (4):5861.

Fung E. H. K., Wong Y. K., Zhang X. Z., etal. Fuzzy logic control of a novel robotic hanger for garment inspection: Modeling, simulation and experimental implementation [J]. Expert Systems with Applications, 2011, 38 (8):9924-9938.

Guo Wenbin, Wang Hongguang, Jiang Yong, Liu Aihua. Obstacle Navigation Planning for a Power Transmission Line Inspection Robot [J]. Robot, 2012 (04):505-512.

Katranik J., Pernu F., Likar B.A survey of mobile robots for distribution power line inspection [J]. IEEE Transactions on Power Delivery, 2010, 25 (1):485-493.

Mateo Sanguino T. J.,Andujar Marquez J. M.Simulation tool for teaching and learning 3D kinematics workspaces of serial robotic arms with up to 5-DOF [J]. Computer Applications in Engineering Education, 2012, 20 (4):750-761.

Mekid S., Labib A. W., Rajemi M. F., etal. Integration of vision and robot motion: A novel approach to teaching kinematics transformation using an industrial robot arm [J]. International Journal of Mechanical Engineering Education, 2011, 39 (3):207-218.

Sun Cuilian, Wang Hongguang, Wang Ludan, etal. An Improved Obstacle Navigation Method of Ultra-high Voltage Power Line Inspection Robot [J]. Robot, 2006 (04):379-384.
Su Wei, Wang Jidai, Sun Aiqin, etal. Expert Control System of Inspection Robot for High Voltage Transmission Line [J]. Computer Engineering, 2012 (15):166-168+171. 